

\title{
DON JOAQUÍN ANTES DE 1975 Adenda para una polémica inconclusa
}

\author{
Manuel Munive Maco \\ Investigador Independiente \\ rupestrecontemporaneo@gmail.com
}

\begin{abstract}
Resumen
A primera vista el "Premio Nacional de Cultura" que se le otorgó en 1975 significó también su consagración como una celebridad en la escena cultural capitalina. Sin embargo, Joaquín López Antay era conocido desde mucho antes gracias a su participación en bienales y ferias limeñas y por las aproximaciones que diversos intelectuales nacionales ensayaron sobre su fascinante quehacer plástico. El presente trabajo aporta información sobre la actividad de Don Joaquín algunos años antes de 1975 en relación con la de John Davis, artista norteamericano que participó en primera línea en el proceso de reconocimiento y divulgación de la plástica tradicional y popular peruanas.
\end{abstract}

Palabras clave: Premio Nacional de Cultura 1975, Joaquín López Antay, John Davis, Bienales de Artesanía, Encuentro Mundial de Artesanías, Art Center Shop, Arte popular peruano.

\begin{abstract}
At first sight it seems that the "National Award of Culture" that was granted to him in 1975 it also meant his "Iaunch" in the cultural scene of the capital. However, Joaquin Lopez Antay was known since much earlier thanks to his participation in biennial and fairs in Lima and for the approaches that various national intellectuals made on his fascinating plastic work. The present paper provides information about the activity of Don Joaquin some years before 1975 and in relation with John Davis, an American artist who participated in the process of recognition and dissemination of traditional Peruvian folk art.
\end{abstract}

Keywords: National Prize of Culture 1975, Joaquín López Antay, John Davis, Craft Biennale, World Meet Artisans, Art Center Shop, Peruvian Folk Art.

\section{Recapitulando}

El 25 de diciembre de 1975 el "Gobierno Revolucionario de la Fuerza Armada”, conducido entonces por el General Francisco Morales Bermúdez, anunció la entrega del Premio Nacional de Cultura al "artesano" Joaquín López Antay (Ayacucho, 1897-1981). El jurado calificador, integrado por el crítico de arte Alfonso Castrillón, los artistas plásticos Cristina Gálvez, Leslie Lee y Carlos Bernasconi, la coreógrafa Vera Stasny, el arquitecto Juan Günther y el musicólogo Enrique Pinilla, dio su veredicto luego de varios meses de deliberaciones. La ceremonia de premiación se realizó en Lima en enero de 1976.

Han pasado cuarenta años desde aquella distinción que tuvo profundas repercusiones en la cultura artística local: no sólo compulsó las artes tradicionales y populares andinas con las artes urbanas y eruditas, reorientando nuestra atención hacia ese universo plástico tal como lo habían propiciado los indigenistas en la primera mitad del siglo XX, sino que produjo una inesperada escisión entre el gremio artístico: por un lado estaban aquellos que se 
sentían "ofendidos" por esa distinción oficial a un artesano sin formación académica y por el otro, aquellos que la celebraban efusivamente por su clarividencia estética.

Para muchos, ese premio que destacaba la obra de un "artesano" andino, fue un "descubrimiento" connatural a la política de puesta en valor y legitimación de las expresiones plásticas del "Perú profundo" de aquella dictadura militar peculiarmente nacionalista y de izquierda. Sin embargo, ya desde los años cuarenta y con más incidencia a lo largo de la década de los sesenta, el trabajo de López Antay y otros autores igualmente importantes, se divulgó en Lima mediante exposiciones comerciales y en bienales especializadas que habían contado con el firme respaldo del Presidente Fernando Belaunde, el mandatario que sería depuesto por el mencionado gobierno militar.

\section{Don Joaquín y sus interlocutores}

No somos para nada "originales": también nos habría gustado conocer a Joaquín López Antay, el legendario retablista huamanguino y probablemente el artista popular peruano más célebre y paradigmático de todos los tiempos, y prolongar la larga lista de los que visitaron su taller en Huamanga o lo conocieron en Lima, durante la visita que hizo para recibir el premio que desató aquel "laberinto".

La prensa de entonces y las personas que conocemos y asistieron a la premiación y a las mesas redondas alusivas coinciden en destacar la serenidad -o el autocontrol- con el que Don Joaquín enfrentó las, a veces, acres discusiones sobre su trabajo. Y si antes esa actitud nos pareció encomiable hoy nos parece lógica, sobre todo si consideramos que nuestro artista estaba literalmente habituado a concitar la atención con su arte. Recordemos que durante décadas su taller de Huamanga acogió a pintores, coleccionistas, antropólogos, periodistas y, sin duda, a curiosos, desde aquel ya mítico día de 1942, cuando la pintora

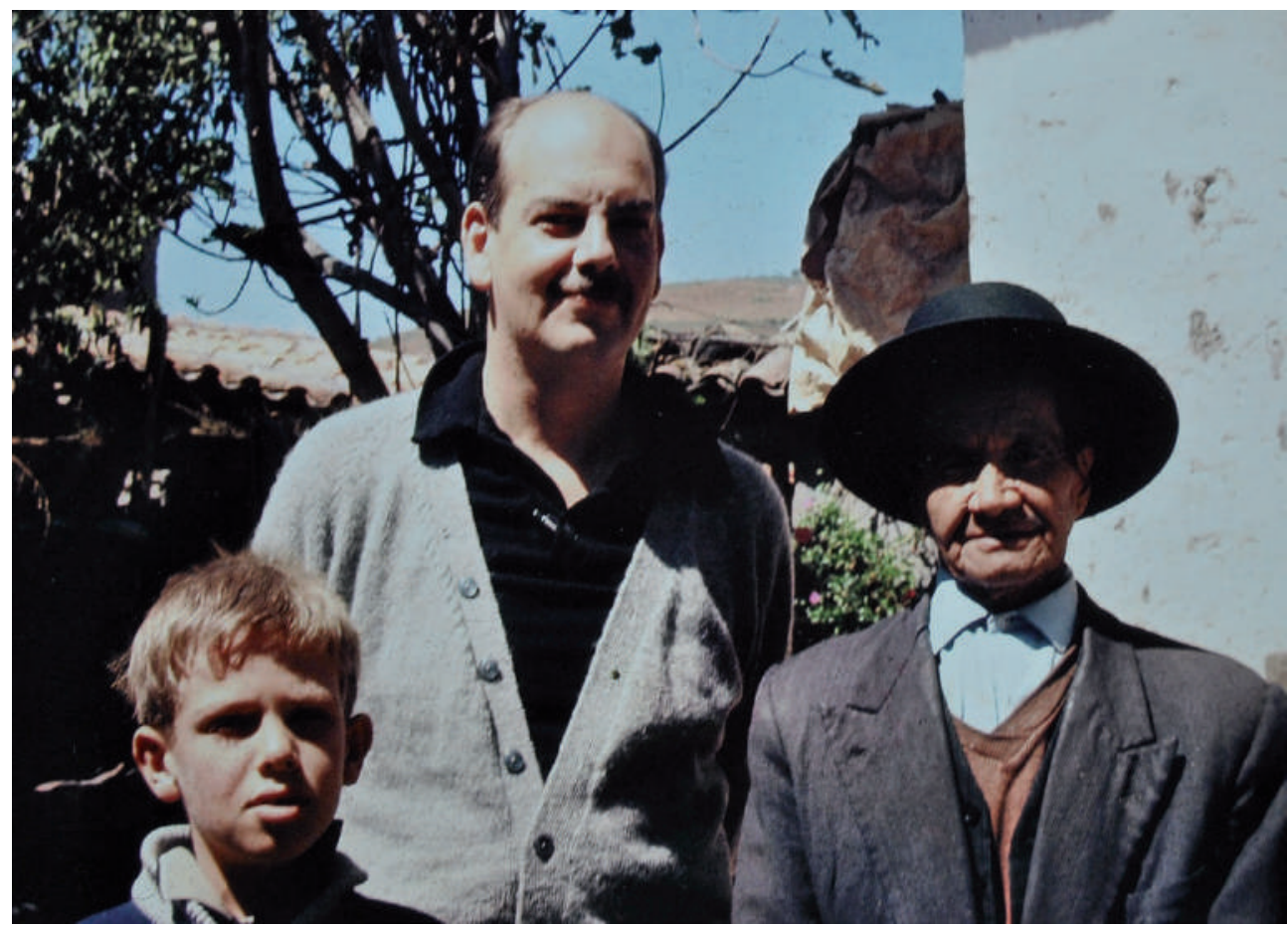

Fig.1. Christopher Davis Benavides, John Davis y Joaquín López Antay en Huamanga (ca. 1963). Archivo Davis Benavides. 
indigenista Alicia Bustamante, lo conoce y le "sugiere" que, ante su visible capacidad de elaborar universos tridimensionales miniaturizados, represente la "Cárcel de Huamanga". El retrato que le hace Enrique Camino Brent en 1959 nos lleva a pensar en que todos los indigenistas debieron pasar por allí después del "descubrimiento" de la Bustamante y, posteriormente, otros intelectuales de la talla de José María Arguedas o Emilio Mendizábal Losack, quienes publican en 1958 y 1964, respectivamente, estudios etnológicos y de historia del arte, en los cuales mencionan a López Antay, nos permiten colegir que éste estaba perfectamente familiarizado con ese trato respetuoso y admirativo que propiciaba. Don Joaquín sabe que lo que hace es imprescindible para su comunidad y tiene, curiosamente, un atractivo "especial" también para los fuereños, incluso para algunos que vienen desde muy lejos, como sucedió con el artista plástico norteamericano John Davis.

\section{John Davis y el Art Center}

John Davis (Wisconsin, 1923 - Lima, 2014) se formó como pintor en el Instituto de Arte de Chicago entre los años 1944 y 1948 y se desempeñó como docente, inmediatamente después, en la Universidad de Syracuse, en Nueva York, donde tuvo a su cargo los cursos de diseño, grabado, arte publicitario y dibujo. Allí conoce a una joven peruana estudiante de escultura, discípula del exigente y famoso Iván Mestrovic, con la que se casará en Lima en 1951 y hará un iniciático viaje de "Luna de Miel" al Cusco, pocos meses después del último terremoto que modificó la fisonomía de la ciudad inca. Recorrer además Ollantaytambo y un Machu Picchu sin turistas, asistir en Pisaq a una misa en quechua y recorrer su mercado de artesanías así como visitar los claustros de las iglesias cusqueñas y sus casonas medio derruidas, obró en la pareja un efecto de encantamiento que tuvo consecuencias: después de unos años en Nueva York, John renunció a su

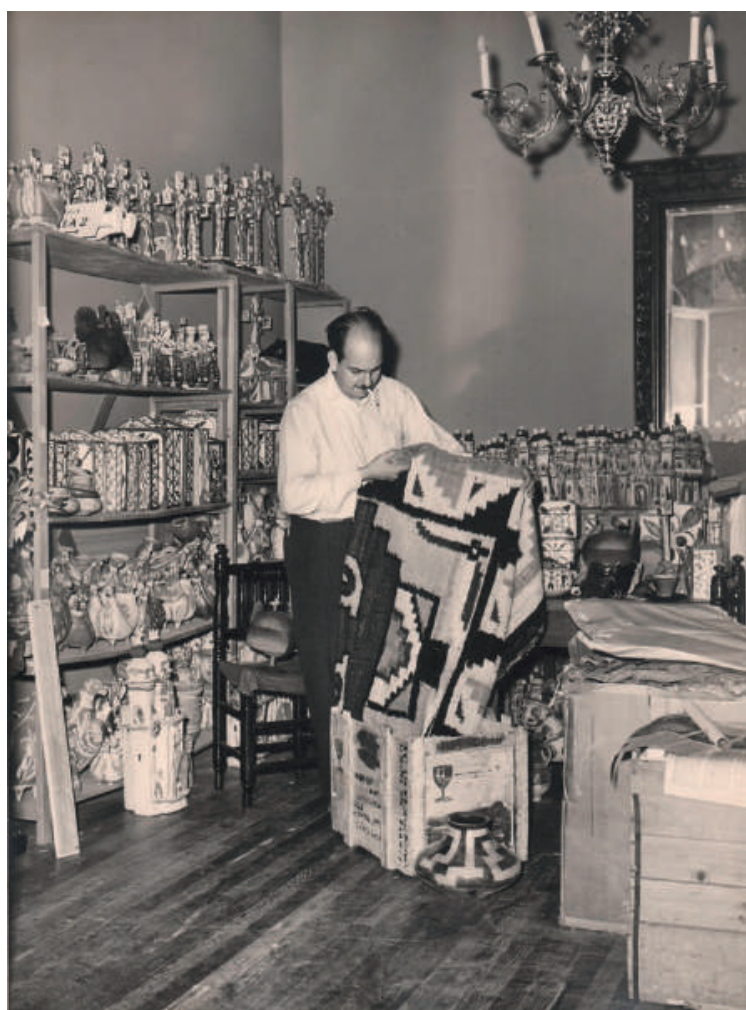

Fig.2. Art Center Shop. Av. Ricardo Palma, Miraflores (ca. 1965). Archivo Davis Benavides. puesto en Syracuse y decide radicar con su familia en el Perú, tal como ocurrió en 1954.

Ese mismo año John Davis e Isabel Benavides fundaron en Miraflores el Art Center, una escuela libre de arte en la que se impartían cursos de "Artes plásticas" para aficionados y que, poco a poco, fue ampliando sus actividades, habilitando una galería en la que se exhibía tanto la plástica erudita como la popular y tradicional así como una tienda -el Art Center Shop- en donde la alfarería de Quinua, los retablos huamanguinos y la textilería andina, entre muchos otros géneros, se ofrecían al público, previamente seleccionados por el buen ojo de ambos. Fue a partir de entonces que John organizaría sus legendarios tours anuales a Ayacucho por Semana Santa, en los que él era el guía y animador, y a través de los cuales afianzaba su relación con artesanos como Jesús Urbano y su maestro, el reconocido Joaquín López Antay, 
entre otros, tal como lo demuestra el retrato fotográfico que le tomó hacia 1960.

En el archivo de documentos de la familia Davis Benavides encontramos algunos recibos y facturas firmadas por varios artistas como el burilador de mates Faustino Dorregaray, el alfarero Saturnino Cutipa, el hojalatero Antonio Prada, los retablistas Joaquín López Antay y Jesús Urbano, y otros, en los que consignan la tipología y el número de las piezas que enviaban a Lima, para su comercialización en el Art Center Shop, entre los años 1961 y 1970.

Específicamente en las facturas que registran los lotes procedentes del taller de Don Joaquín -se conservan cuatro: tres de 1964 y una de $1965^{1}$ - vemos una variada tipología de piezas así como distintos volúmenes: 31, 23, 5 y 42 objetos entre retablos -"Huida a Egipto", "Virgen de Copacabana", "Nacimiento", "San Antonio" y uno de ellos denominado "retablo anda"-, cruces de varios tamaños así como figuras como "Morochucos", numerosas "ollitas", y un, para nosotros, insólito "Nacimiento de San Hilarión" en piedra de Huamanga.

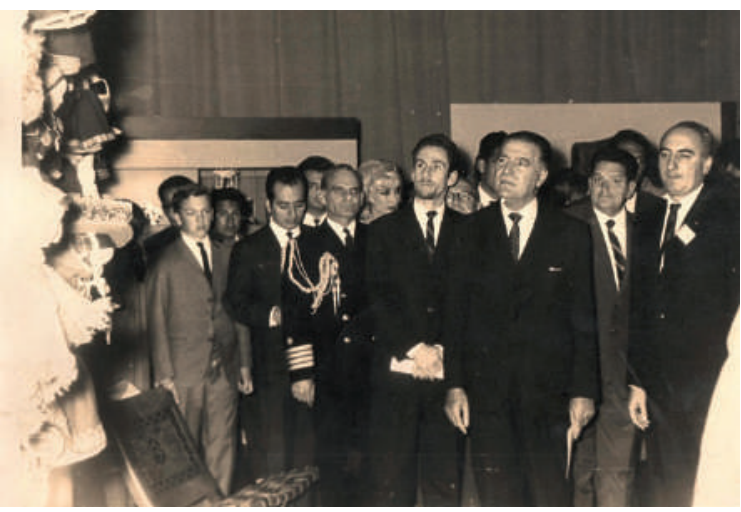

Fig.3. Inauguración de la 1ª Bienal de Artesanía. Stastny, Belaunde y Bernasconi. Museo de Arte de Lima. 1966.

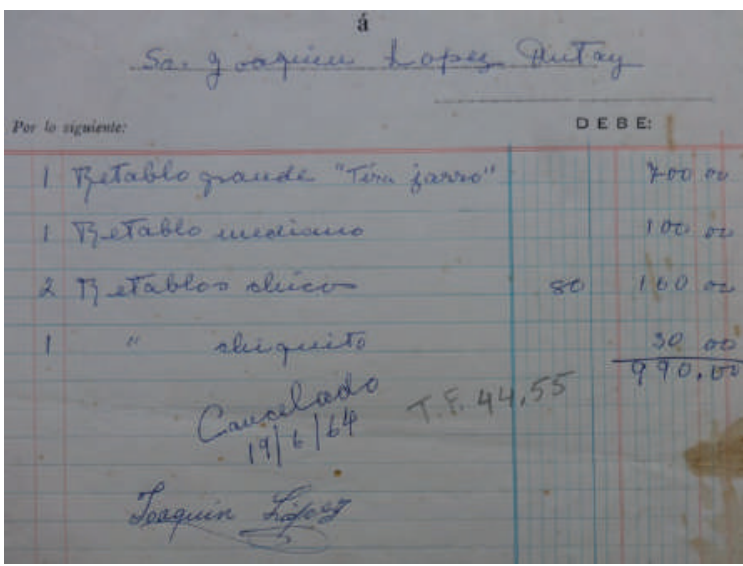

Fig.4. Factura del Art Center Shop firmada por Joaquín López Antay el 19 de junio de 1964. Archivo Davis Benavides.

Destacamos particularmente el "encuentro" de Davis con López Antay pues la suya era una mirada distinta de la de un pintor indigenista, de la de un etnógrafo o de la de un historiador del arte nacidos en el Perú: se trataba de la observación de un artista formado en el Instituto de Arte de Chicago, una de las mejores escuelas de arte de los Estados Unidos, que había trabajado como guía y vigilante en las salas del Museo de Arte de su alma mater -en donde tuvo las primeras noticias del Perú mediante su colección de ceramios precolombinos- y con conocimientos de diseño y grabado. Davis, por otro lado, desconocía el complejo periplo formal que había desembocado en ese curioso y emblemático objeto llamado "retablo" de modo que lo que capturó su atención fueron sus cualidades estéticas. (Algo semejante pasará, veinte años después, con el crítico Alfonso Castrillón quien, formado como historiador del arte en Roma, descubre a López Antay durante su trabajo como miembro del jurado y, sin embargo, reconoce también de inmediato que estaba ante una figura trascendental y con la que se inauguraría un nuevo capítulo de nuestra historia del arte).

Parece que éste y otros encuentros -con ceramistas, buriladores de mates, imagineros y tejedores- hacen que Davis deje en suspenso su carrera artística y decida, a cambio,

1 Fechadas el $1^{\circ}, 29$ de abril y 19 de junio de 1964 y el 27 de julio de 1965 . 
sumergirse en ese todavía inexplorado universo de formas plásticas cuyo valor indudable él, como pocos entonces, era capaz de valorar a cabalidad, y con las cuales se relaciona desde varios aspectos: como artista -no olvidemos que era también ceramista-, como divulgador -mediante la organización de exposiciones y comerciando sus especímenes- así como consultor y conservador, etc. Por eso Isabel nunca exhibió su obra individualmente en la galería del Art Center y John solo una vez durante los veinte años que permaneció abierta al público. Ambos, pero particularmente John, consagran tiempo y esfuerzo en trabajar por la valoración y la divulgación de las expresiones plásticas tradicionales del Perú, como lo evidencia su contribución con la "Escuela de Artesanía" fundada en Ayacucho por Jesús Urbano a inicios de la década de los sesenta.

Entre las exposiciones más significativas realizadas en la galería del Art Center mencionamos precisamente la del retablista e imaginero Jesús Urbano así como la novedosa muestra dedicada íntegramente al tradicional sombrero de paja de Chilca en febrero de 1965. Otras igualmente notables fueron, la Primera exposición de artesanos de Puno, inaugurada en octubre de 1965, o la muestra de Artesanía del Valle del Mantaro realizada en agosto de 1966. Todo estaba por descubrirse en el ámbito del arte tradicional y popular peruanos y John Davis lo sabía.

\section{Una Bienal, una Feria y un Congreso de Arte Popular}

Antes del mencionado "descubrimiento” de López Antay se habían producido algunos otros "eventos" en cuya realización estaba involucrado también John Davis. Destacamos aquí tres de ellos:

a) la creación de la Bienal de Artesanía en 1967 (que tuvo una segunda edición en 1969);

b) el viaje de una delegación de artistas populares peruanos a California en 1967 -entre ellos Hilario Mendívil y Jesús Urbano-, para exponer y hacer

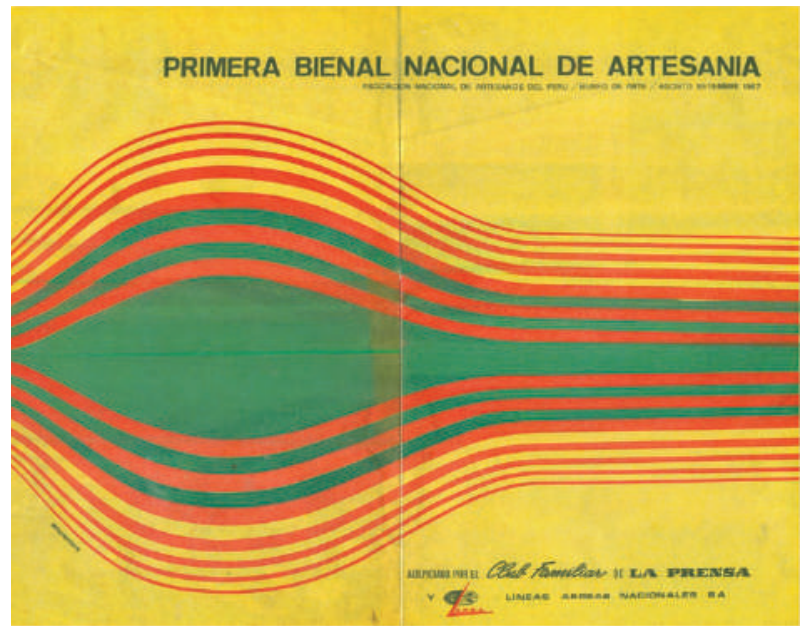

Fig.5. Afiche de la Primera Bienal Nacional de Artesanía 1967. Diseño José Bracamonte Vera. una demostración de sus procedimientos técnicos en la Feria Anual de Los Ángeles; y,

c) el III Encuentro Mundial de Artesanos, realizado en Lima en 1968, gracias a que, desde 1964, John Davis era representante en el Perú del Consejo Mundial de Artesanos. (A este congreso, que se llevó a cabo en el centro recreacional de Huampaní, asistieron 800 artesanos procedentes de 45 países de los 61 que integraban el Consejo Mundial². Las ediciones anteriores se habían celebrado en Nueva York y en Montreaux).

Echarle un vistazo a la nómina de expositores de la Primera Bienal Nacional de Artesanía, realizada en agosto y septiembre de 1967, implica encontrarse con aquellos artistas populares

2 Países con representaciones en Huampaní: Alemania, Australia, Austria, Bélgica, Bolivia, Brasil, Canadá, Ceilán, Checoslovaquia, Chile, Colombia, Costa de Marfil, Dinamarca, Ecuador, España, Estados Unidos, Francia, Ghana, Grecia, Guatemala, Haití, Holanda, India, Indonesia, Irlanda, Israel, Italia, Japón, Liberia, Malasia, México, Marruecos, Nueva Zelanda, Nigeria, Noruega, Panamá, Paraguay, Perú, Reino Unido, Sikkim, Suecia, Suiza, Tailandia, Turquía y Venezuela. 
que poco tiempo después serían legendarios. Entre ellos figura Joaquín López Antay así como Florentino Jiménez y Jesús Urbano en "Retablos"; a Apolonia Dorregaray y Catalina Zanabria en "Mates burilados"; a Leoncio Tineo y Edilberto Mérida en "Cerámica tradicional" y a Maximiliana Palomino y Enrique Sierra en "Muñequería".

Lamentablemente el apoyo para producir la segunda edición de la bienal, y más aún la tercera, realizada en 1971, fue mermando ostensi-

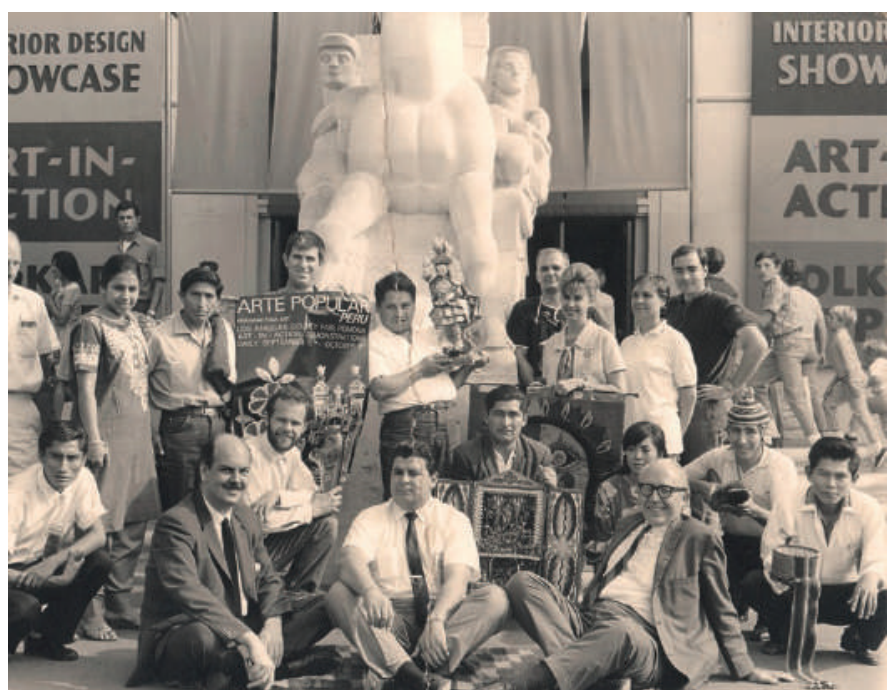

Fig.6. Artistas populares peruanos en feria de Pomona, California. 1967. Archivo Davis Benavides.

blemente. La Junta Militar que había dado el golpe al Presidente Belaunde Terry a fines de 1968 parecía no ver con buenos ojos las iniciativas culturales vinculadas con el arquitecto: recordemos que este, había inaugurado la primera bienal así como el gran encuentro de artesanos en Huampaní. Y esto resultó adverso también para la pareja Davis Benavides.

\section{Otros actores: Margarita y Francisco Meléndez}

Entre los documentos del archivo Davis Benavides destacan también las facturas firmadas por la señora Margarita Meléndez, cuya participación en la difusión del arte popular en Lima merece destacarse pues fue gracias a la disponibilidad del camión de su esposo que llegaban a la feria de "El Porvenir" los primeros lotes con especímenes de arte popular que ella reunía y comercializaba también en su establecimiento de Ayacucho ${ }^{3}$. Francisco Meléndez era un distribuidor de materiales de construcción ${ }^{4}$ que acopiaba mercancías periódicamente en Lima y para que el camión no llegara vacío, su esposa lo fletaba con piezas de alfarería, retablos y otros objetos que dinamizaron la difusión de las formas plásticas populares en la capital, enriqueciendo las colecciones más antiguas y creando, a su vez, nuevos aficionados.

Por ejemplo, en la factura del 19 de octubre de 1961 se detalla un lote de más de 400 piezas integrado por caballos, toros, cálices, teteras, tinajas, platos, jarras, botijas, iglesias, músicos, "chunchos", "virgencitas", etc. Los esposos Meléndez participaron también activamente en la realización de los tours organizados por John Davis a Ayacucho durante la Semana Santa, preparando recepciones y actividades de esparcimiento -como el concurso de cerámica- en su hacienda Tinajeras.

\section{Colofón}

Paradójica es la circunstancia que determina el fin del Art Center: durante las mismas semanas en que se otorga el Premio Nacional a Don Joaquín, Isabel, en su calidad de

3 Artes populares. Sra. Margarita Gutiérrez de Meléndez. Jirón Grau No 207. Cerámicas diversas de Quinua: renombrados toritos e iglesias. Retablos huamanguinos. Variedad de tejidos ayacuchanos y objetos de arte". Limaco, César Augusto. "La ciudad de Ayacucho, Guía para turistas". Ayacucho, 31 de octubre de 1961.

4 "Distribuidor autorizado de Cemento Andino S. A. Fabricante de ladrillos, tejas, losetas venecianas, (...) fierros de construcción, calaminas. Se alquila volquetes...”. İ́dem. 
"Directora-gerente", tiene que sustentar ante "el Director de la Zona de Educación No 4", que la multa por una supuesta "infracción" no tiene fundamento y que, además, la crisis financiera que atravesaba la institución los estaba obligando a clausurarlo. A esto había que agregar que entonces John no se encontraba en el Perú por las hostilizaciones del Gobierno Militar que, absurdamente, creía ver en su labor peruanista la sombra de la "CIA y del imperialismo". ¿Esto fue parte de un calculado proceso de silenciamiento? No lo podríamos asegurar aunque gran parte de los hechos "encajan": estas hostilidades parecían recaer sobre la persona que había dedicado muchos años de su vida en destacar el trabajo de artistas como López Antay y bajo la anuencia del Presidente Belaunde.

Fue por esta injusta circunstancia que los Davis no pudieron celebrar la distinción nacional que se le había adjudicado a Don Joaquín, distinción para la cual, y desde mucho tiempo atrás, ellos habían contribuido silenciosamente.

Finalmente, más allá de revelar "quién era quién" en el gremio artístico, la inspirada premiación a Don Joaquín aportó varias ideas, entre ellas, la necesidad de hacer una diferenciación entre la artesanía y el

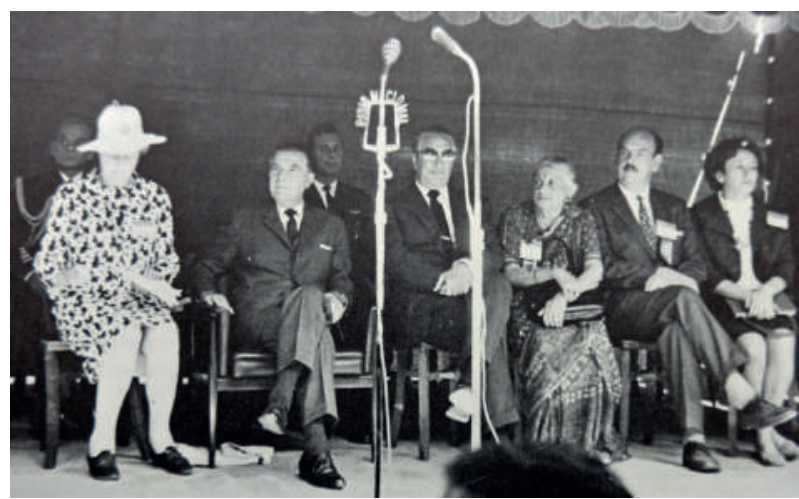

Fig.7. Inauguración $3^{\text {er }}$ Encuentro Mundial. Presidente Belaunde, A. Vanderbilt, Isabel y John Davis y otros. 1968. arte popular, así como de un término que sirviera para designar a López Antay y a otros artífices como él. Fue así que empezaron a difundirse, lentamente, -aún hoy existen quienes no perciben la diferenciaconceptos como "arte popular" y "artista popular". La contribución de Alfonso Castrillón en este aspecto resultó muy valiosa, pues al haber sido el crítico de arte que integraba el jurado 5 que otorgó el premio -lo que implicó que fuera considerado "persona no grata" por la Asociación Peruana de Artistas Plásticos- le correspondió la teorización sobre aquel fenómeno puesto abruptamente sobre el tapete.

\section{Referencias}

Documentos sobre el Art Center Shop procedentes de archivo de la familia Davis Benavides.

Munive, M. (2015). Isabel Benavides y John Davis, impulsores de las Artes, ICPNA. Editorial ICPNA 2015.
Castrillón, A. (2015). "Tópicos sobre Arte Popular: 40 años del Premio a López Antay" en Revista Illapa Mana Tukukuq, №12 año 12:1324. Revista del Instituto de Investigaciones Museológicas y Artísticas. Editorial Universitaria de la Universidad Ricardo Palma. Lima 33.

5 Leslie Lee fue quien sugirió la candidatura del retablista, que fue respaldada unánimemente por los miembros del jurado. 